\title{
O modelo das forças de Porter e posicionamento estratégico como diferencial competitivo: o caso de uma empresa no ramo de bebidas
}

Diego Felipe Rodrigues Ferreira Prata

diegoengenharias@yahoo.com.br

diegoengenharias@yahoo.com.br
Instituto Federal do Espirito Santo (IFES),

Guarapari, Espírito Santo, Brasil

Elias Rocha Gonçalves Júnior Elias Rocha Gonçalves
eliasrgjunior1@gmail.com

Faculdade Brasileira - Multivix Vitória (MULTIVIX), Vitória, Espírito Santo, Brasil

Virgínia Siqueira Gonçalves virginiasiqueiragoncalves@gmail.com Instituto Federal de Educação, Ciência e Tecnologia Fluminense (IFF), Campos dos Goytacazes, Rio de Janeiro, Brasil

Paulo Rossi Croce

paulorossicroce@gmail.com

Instituto Federal de Educação, Ciência e Tecnologia Fluminense (IFF), Campos dos Goytacazes, Rio de Janeiro, Brasil

\begin{abstract}
RESUMO
As empresas do ramo de bebidas são organizações que estão constantemente buscando maneiras mais eficientes de satisfazer as necessidades dos clientes. Cada organização utiliza-se de diversas estratégias com o objetivo de atingir mais compradores sem comprometer a sua existência e a sua vantagem competitiva. Este trabalho baseia-se nas cinco forças competitivas e na teoria das estratégias competitivas genéricas de Porter que estabelece em seu modelo que as empresas pertencentes ao mercado devem possuir, no mínimo, uma das três abordagens estratégicas: diferenciação, enfoque e liderança no custo. Será identificado e descrito o modo de atuação das cinco forças competitivas de Porter e como elas influenciam na definição da estratégia competitiva empresarial. Inicialmente, procurou-se realizar o levantamento da relação das estratégias da empresa em estudo com a teoria apresentada por Porter e foram aplicados questionários aos gerentes setoriais da empresa em questão. Após a análise destes questionários, foram identificados três agrupamentos setoriais com abordagens válidas. Posteriormente, foram selecionadas as respostas correlacionadas que possuíam maior afinidade entre os setores e que melhor representavam os resultados dispostos acerca da teoria proposta e, nesta amostragem, foi realizada uma entrevista com o gerente geral. 0 resultado observado a partir da entrevista validou a análise dos dados encontrados nos questionários aplicados anteriormente, demonstrando conformidade com o referencial teórico. Pode-se afirmar que, com os resultados obtidos, é válida a aplicação desta teoria na empresa comercial de bebidas, a qual vem se adequando para maximizar os resultados financeiros e aperfeiçoar o posicionamento estratégico em relação aos seus concorrentes.
\end{abstract}

PALAVRAS-CHAVE: Setor de Bebidas. Modelo de Forças Competitivas de Porter. Estratégia empresarial. 


\section{INTRODUÇÃO}

A globalização e as rápidas mudanças tecnológicas vêm alterando a forma de concorrência e o padrão de competitividade entre as empresas, afetando todos os setores em diferentes níveis. Diante disso, as empresas que desejam permanecer competitivas são obrigadas a ter uma visão estratégica do ambiente em que se encontram inseridas. De acordo com Kotler (1998), o ambiente empresarial tanto oferece oportunidades quanto ameaças e as empresas bem-sucedidas sabem que são vitais a observação e a adaptação constantes às mudanças do ambiente.

Cabe dizer que "ambiente é tudo aquilo que envolve extremamente uma organização" (CHIAVENATO, 2004). Como o ambiente organizacional é amplo, pois está além das fronteiras ou limites da organização, torna-se inviável analisá-lo e compreendê-lo na sua totalidade, necessitando-se, com isso, ser desdobrado em dois segmentos: macroambiente e microambiente.

Segundo Chiavenato (2004), o macro ambiente é o meio mais amplo que envolve a empresa, bem como a sociedade que está inserida. Funcionam de forma ampla abrangendo todos os componentes integrantes dos fenômenos econômicos, tecnológicos, sociais, legais, políticos, demográficos, ecológicos, dentre outros que influenciam a organização. Dessa forma, a análise externa está diretamente ligada para o macro ambiente, de modo a oferecer informações sobre as forças impulsionadoras e condicionadoras para a organização.

A estratégia é uma combinação das metas que a empresa busca alcançar e das políticas que ela promove para chegar a seus objetivos. 0 desenvolvimento de uma estratégia competitiva é o desenvolvimento de uma fórmula ampla que abrange todo o modo como uma empresa competirá em seu mercado (PORTER, 1999).

As empresas que buscam evoluir estabelecem uma postura estratégica mais adequada para alcançar seus próprios dentro da missão empresarial, respeitando sua situação interna e externa. Uma estratégia pressupõe a definição de objetivos a serem cumpridos e recursos a serem dispostos, viabilizados através de sua estrutura organizacional (OLIVEIRA, 2005).

As empresas costumam possuir características mais específicas quanto à formação de suas estratégias agindo de acordo com esta política. Outras empresas se voltam ao controle, manutenção e acompanhamento dos custos em busca de maximização dos resultados ou até mesmo da adequação a regras de mercado; algumas voltam para o estabelecimento sistemático de procedimentos, produtos e técnicas de excelência, oferecendo aos clientes um nível de diferenciação em busca de uma viagem maior em relação à concorrência. Há também outras empresas que buscam um nível de enfoque elevado para atingir rigorosamente um determinado segmento ou tipo de cliente específico (PORTER, 1999).

Os elementos de seu ambiente relacionados com os objetivos da empresa dão origem ao que Porter (1999) define como forças competitivas, a partir daí supõe que uma estratégia eficaz deve levar em consideração o maior objetivo de qualquer empresa que é ter uma elevada barreira a entrada de novos competidores, aumentando o seu poder de barganha em relação aos fornecedores e intermediários, e com isso criar para seus 
serviços ou produtos vantagens que podem ser observados como diferença pelos consumidores; criando uma forte posição competitiva.

Assim, diante da definição do Porter (1999), onde posiciona as estratégias em três abordagens genéricas: liderança de custo, diferenciação e enfoque, sendo ambas tratadas pelo autor como métodos alternativos viáveis para lidar com as forças competitivas. Segundo o autor, cada empresa utiliza uma estratégia competitiva enquadrando-se em uma dessas abordagens, sendo assim o trabalho pretende posicionar de forma qualitativa, em seu modelo, a indústria de bebidas aqui denominada $\mathrm{T}$.

Dessa forma, este trabalho de pesquisa buscará a identificação das estratégias competitivas utilizadas pela empresa aqui denominada $T$, para ser mantido seu anonimato. Tendo em vista o notável crescimento da empresa em estudo do ramo do setor de bebidas e sua aspiração a outros mercados em potencial, o presente estudo visa analisar os mecanismos estratégicos utilizados pela empresa para se desenvolver em mercados já conquistados e em mercado potencial, averiguando de que maneira as cinco forças Porter agem na empresa e quais os reflexos para a competitividade da mesma e também pretende servir como referência para estudos evolutivos, tanto no setor de bebidas quanto em outros setores industriais.

\section{FUNDAMENTAÇÃO TEÓRICA}

Com o crescimento da economia global, fortes mudanças vêm acontecendo em todos os seguimentos de mercado. Antigamente, apenas as empresas de grande porte e indústrias se preocupavam em estabelecer estratégias e controles sofisticados para garantir reduções de custos, mas tendo em vista à concorrência através das fronteiras nacionais às empresas de menor porte, sejam elas indústrias ou comércio, vêm também se preocupando em acompanhar o processo evolutivo do atual cenário competitivo (GONÇALVES; PAIVA JR., 2006).

De acordo com Silva Neto (2002), dando ênfase a uma visão sistêmica, existem pressões internacionais, locais e nacionais em todo segmento industrial variando de intensidade proporcionalmente com a fatia de atuação da empresa no mercado. Segundo o autor, quanto maior a fatia de atuação maior será a intensidade de pressões competitivas. $O$ autor define que certas cadeias produtivas possuem características específicas que determinam se estas pressões são positivas e negativas, onde ele exemplifica positivamente uma indústria de bebidas, foco de trabalho, e negativamente o setor de computação, onde devido à maior intensidade das pressões a lucratividade tende a ser menor devido aos altos e constantes custos de investimentos necessários para se mantiver competitivo.

Uma tendência mundial é a de que, diferentes clientes, simultaneamente, aspiram às mesmas coisas devido aos avanços tecnológicos tornando o mundo dos negócios cada vez mais centralizado e mais acessível a um número muito maior e mais exigente de consumidores (COGAN, 2006). 
Segundo a Nielsen, no período de 1990 a 1998, houve um crescimento no mercado brasileiro de 55\%. Tradicionalmente, na última década, o Brasil ocupou a sexta posição entre os maiores produtores de cerveja. A produção do Brasil, em 1998, foi de 8,17 bilhões de litros de 55 fábricas instaladas no país da época.

Segundo Rebouças (2009), no Brasil o setor de bebidas teve um crescimento de 69,7\% no período de 1990 a 2005. Em 1998, o consumo por pessoa no país havia sido de 328 litros, abaixo do consumo da Europa e dos EUA. Na Europa, o consumo havia sido de 553 litros e, nos EUA, de 620 litros por pessoa.

Ainda de acordo com o autor supracitado, em 2005 os produtos de consumo de massa registraram um crescimento de $4,8 \%$, enquanto que a produção de bebidas não alcoólicas teve um crescimento de $5,4 \%$. No mesmo ano, a produção de bebidas alcoólicas manteve-se estável, com uma leve queda de $0,3 \%$ na comercialização. A queda de produção e vendas de bebida alcoólica em 2005 ocorreu devido à queda da Aguardente de Cana (cachaça) no mercado.

Em 2009, segundo dados publicados pela Nielsen, o mercado da cerveja no Brasil cresceu acima de $5 \%$, ultrapassando a produção da Alemanha no ranking mundial. $O$ crescimento é justificado pelo consumo crescente da Classe $C$, pelo planejamento de marketing das marcas e a comercialização de formatos de 1 litro e $260 \mathrm{~mL}$. Entre janeiro e novembro de 2009 , em comparação a 2008, o faturamento das fábricas de cerveja no Brasil teve um aumento de $11 \%$, com acréscimo médio de valor por litro de $7,3 \%$.

Conforme Porter (1999), a competição intensificou-se de forma drástica, em praticamente todas as partes do mundo. Há não muito tempo atrás, a competição era quase inexistente em muitos países e setores. Os mercados em geral, protegidos e prevaleciam as posições de dominação. Mesmo quando existia concorrente, a rivalidade era menos intensa. A sufocante intervenção governamental e os ostensivos cartéis minimizavam a competição.

A agilidade, a melhoria contínua, e a luta incessante contra o inconformismo dos padrões de qualidade pouco desafiadores são focos das modernas organizações. Atualmente, nenhuma empresa e nenhum país têm condições de ignorar a necessidade de competir. Todas as empresas e todos os países devem procurar compreender e exercer com maestria a competição. É fundamental, entretanto, a consciência de que atualmente não são apenas os ciclos de vida dos produtos que estão escolhendo, mas que os ciclos de vida das estratégias também estão mais breves e que, assim sendo, as empresas devem manter constantemente monitoramento e tornarem-se ágeis na formulação de suas estratégias (WRIGHT, 2000).

O atual contexto mundial, caracterizado pela globalização, pela alta competitividade, crescente importância dos serviços, exigência por rapidez, e personalização está forçando as empresas repensarem a organização de seus negócios. Quanto maior for a velocidade das mudanças, maiores as incertezas, assim surge a necessidade de criar sistemas de informações flexíveis e competitivos, viabilizando a comunicação clara e resultados otimizados. O consumidor e o cliente, cada vez mais exigentes, limitam 
espaços para erros contínuos, como: atrasos nas entregas ou informações confusas (CUNHA, 2006).

Segundo Oliveira (2005), a estratégia empresarial é um assunto que vem ampliando seus horizontes devido ao alto nível de acesso à informação na atualidade e também ao elevado grau de penetração das organizações. Diferente do que acontece hoje, a estratégia era um procedimento restrito às grandes instituições que precisavam de um planejamento mais complexo para manter suas expectativas empresariais.

A Estrutura de Cinco Forças da Porter foi descrita pela primeira vez em um artigo da Harvard Business Review (PORTER, 1979) e foi revisado em 2008 (PORTER, 2008). O modelo de Porter aplica uma estrutura rigorosa e validada para entender a concorrência da indústria através de cinco forças: rivalidade entre concorrentes existentes, ameaça de novos concorrentes, poder dos compradores, poder de fornecedores e ameaça de substitutos (PORTER, 1979).

Para Lakatos e Marconi (2000), a identificação dos fatores internos da empresa, com seus pontos fortes e fracos, assim como, o monitoramento dos fatores externos, através do levantamento das oportunidades e ameaças, possibilitará mensurar o nível de preparação da empresa para a inserção na cadeia produtiva de seu segmento. Outro aspecto de igual relevância refere-se à identificação dos fatores e condicionantes de competitividade de cada cadeia produtiva, de modo a possibilitar o conhecimento das razões de seu desempenho, bem como a viabilidade de seu ingresso. Todo esse mapeamento de informações tem como objetivo principal facilitar a definição das ações que tornarão viáveis as metas então propostas.

Diversos autores usaram o Modelo das Cinco Forças de Porter em estudos estratégicos de setores específicos, entre os quais podemos destacar sua aplicação na análise de mudanças no ambiente de segurança marítima (YETKIN, 2013), na busca por estratégia de liderança de diferenciação e alto valor no mercado de cirurgia vascular (SUMPIO, 2013), na indústria de vestuário (AKÇAGÜN; DAL, 2013), na análise de empresas de supervisão de engenharia e a construção de um sistema de crédito (Ql; SUN; CHENG, 2014), na análise de serviços de saúde (O'HARA et al., 2017), na análise de transporte coletivo urbano (ORTEGA; JALÓN; MENÉNDEZ, 2014), na revisão de programas conjuntos de MBA (NGUYEN, 2017) e, por fim, no estudo da situação de mercado de um aeroporto e verificação da tendência atual no setor aéreo (MAN, 2016).

\section{METODOLOGIA}

De acordo com Forte (2006), o objeto do trabalho científico apresentase com a modelagem de modelos teóricos com o objetivo de apoiar as questões ou variáveis a serem analisadas advindas de perguntas de questionário ou roteiro de entrevista.

Na coleta dos dados serão levantadas informações sobre a empresa, através de: questionário e entrevistas (pré-estruturadas) com os gestores, pesquisa documental e observação in loco. A análise dos dados será feita com base no modelo formulado por Porter (1999). 
Nesta pesquisa, serão desenvolvidos e aplicados aos gestores da empresa $T$ roteiros pré-estabelecidos com perguntas abertas a este grupo selecionado da amostra da pesquisa, pela sua maior afinidade com as tipologias das estratégias competitivas genéricas e com isso coletar dados necessários para a identificação da empresa, segundo o modelo de Porter (1999) e também detectar tendências e características da empresa quanto às estratégias competitivas genéricas.

Para a entrevista, serão abordadas questões que abrangem todas as estratégias competitivas objetivando maior confiabilidade no processo investigativo. Para identificar a estratégia nesta organização, serão utilizadas as histórias e experiências da empresa, técnicas e condições de compra e de venda e a clientela, resultados adquiridos que permitam compreender a realidade estratégica atual.

A entrevista acontecerá através de diálogos com o interpelado visando a cooperação empática, o que facilita a absorção das tendências do entrevistado acerca do tema e podendo levar à plena experiência do indivíduo (YIN, 1994).

\section{HISTÓRICO DA EMPRESA}

Em 1908, no norte do estado do Rio de Janeiro, foi fundada a Indústria de Bebidas T. Seu fundador desenvolveu a fabricação de conhaque, produto que mais tarde se tornaria a base da empresa e a ter o nome da cidade como forma de homenagear onde tudo começou.

A qualidade do produto e a fama de curar e prevenir doenças se espalharam pela região, o que fez com que várias pessoas se interessassem pelo produto e com isso em pouco tempo a fama do produto ganhou contornos nacionais e hoje tendo mais de 100 anos de história este produto manteve sua fórmula inalterada segundo seus diretores.

A década de 90 representou um salto tecnológico para a empresa. Nesse período foram inauguradas as novas linhas de produção com novas unidades engarrafadoras dando um grande aumento na capacidade produtiva da empresa. Mediante esse aumento novos produtos foram lançados, as exportações intensificadas e com isso a empresa ganhou cada vez mais espaço e representativa no cenário nacional.

Atualmente a empresa tem aproximadamente $16.000 \mathrm{~m}^{2}$ na sua planta industrial com capacidade para produzir em torno de 50.000 litros/hora utilizando suas duas linhas de produção. Essa grande capacidade produtiva só foi conseguida dentro de elevados investimentos em qualificação da mão de obra e em tecnologia da ponta com a aquisição de máquinas de última geração para a produção e armazenamento de bebidas.

Voltada sempre para a qualidade de seus produtos a empresa $T$ submete todos os seus insumos a rigorosos testes e inspeções de qualidade antes de serem utilizados no processo de produção. Para garantir o padrão de qualidade considerado ideal, a empresa realiza testes físicos e químicos em cada componente dos produtos, desde as embalagens, até os insumos líquidos, utilizados no processo de elaboração dos produtos. 
Segundo o gerente de produção da empresa, os insumos líquidos passam por uma inspeção técnica e se aprovados são armazenados em tanque de inox com capacidade total de 2.500 .000 litros. Esses produtos são adquiridos dos antigos e conceituados fornecedores do mercado. A água utilizada na fabricação das bebidas é coletada, filtrada e monitorada em hora em hora, numa estação de tratamento da própria fábrica e em todas as fases do processo de produção, os técnicos recolhem amostras dos produtos que estão sendo elaborados e realizam os testes necessários para garantir a quantidade final da produção e como prova do compromisso de buscar a melhoria contínua da qualidade a gestão do setor responsável é atestada pela certificação ISO 9001:2008.

Tal compromisso pode ser observado na visão da empresa que é ser uma organização competitiva e inovadora, com excelência em qualidade para ocupar forte posição nacional e alavancar o mercado internacional de bebidas alcoólicas e não alcoólicas. Na missão ela define como pretensão atuar de forma rentável e responsável, sendo reconhecida como criadora do "Conhaque do Milagre"; perpetuando sua tradição secular no desenvolvimento, fabricação e comercialização de bebidas com qualidade e segurança que proporcionem os consumidores momentos de plena satisfação.

\section{COLETA DE DADOS}

Os dados foram coletados através dos instrumentos de pesquisa nos três setores considerados importantes para obtenção dos dados; os quais sejam setor de qualidade, produção e administrativo. No momento da aplicação da pesquisa, foi declarado ao respondente que seus questionários deveriam ser preenchidos de acordo com a realidade apresentada pela empresa, apresentando, sem nenhuma influência externa.

As visitas ocorreram in loco nos setores da empresa e foi dividido em três etapas. Na primeira etapa foi entregue aos gerentes de cada setor apenas um instrumento de pesquisa para que respondessem 0 questionário.

A segunda etapa correspondeu ao recolhimento dos questionários devidamente preenchidos pelos gerentes setoriais. Essa etapa foi mais demorada devido ao atraso da devolução do material de pesquisa respondido integralmente.

Neste momento foi realizada a análise de dados onde foram identificadas e agrupadas respostas que indicavam correlações as três abordagens possíveis apresentadas por Porter (1999) das Estratégias Competitivas Genéricas que são: diferenciação, líder em custo e enfoque, de acordo com a fundamentação teórica apresentada neste trabalho.

Posteriormente, foi aplicada uma entrevista com o gerente geral da empresa abordando as cinco forças competitivas e cada Estratégia Competitiva Genérica para verificar qual abordagem que a empresa se aproxima mais, identificando assim suas estratégias e como esta beneficia a sua empresa objetivando validar os resultados encontrados. 
A aplicação de uma entrevista permitiu averiguar os resultados dos agrupamentos obtidos na análise setorial e complementou o estudo com uma abordagem qualitativa fundamentada ainda mais as análises realizadas nos três setores. A entrevista aconteceu de forma semiestruturada devido ao fato de seguir o roteiro prévio de questões apresentadas no apêndice I deste trabalho, mas, ao mesmo tempo, permitindo que o entrevistado emitisse seu parecer do tema através da conversação com o entrevistador.

\section{RESULTADOS E DISCUSSÃO}

Em todo o percurso desta entrevista foi feita uma associação do relato das experiências do entrevistado com a base teórica das Estratégias Competitivas Genéricas. $O$ indivíduo entrevistado foi o gerente geral da empresa T, aqui denominado como GGT. Através dessa relação, é possível perceber o seu posicionamento sobre cada abordagem confirmando ou não se o posicionamento da empresa está convergente com o apresentado na análise do enquadramento da empresa ao modelo de Porter (1999).

As perguntas foram voltadas para atingirem as três estratégias (custo, diferenciação e enfoque) para que houvesse maior confiabilidade no processo investigado e no sucesso da entrevista, mas também para que por fim se pudesse confirmar ou não os dados apresentados nas análises setoriais.

O gerente GGT relatou a situação que se encontra a empresa que gerencia como bem-sucedida no mercado e que as estratégias adotadas satisfazem as expectativas quanto aos resultados. Ao ser questionado quanto à importância e preocupação com os custos para a empresa $T$, respondeu o seguinte discurso, no trecho 01: "nós trabalhamos com produtos selecionados e de boa qualidade e nos cobramos mais de que outras empresas... Como os custos são altos, nós repassamos em preço para o cliente, pois ele está pagando mais por um produto de qualidade".

De acordo com Porter (1999), a vantagem no custo exige despesas indiretas extremamente baixas e uma fonte abundante de mão de obra de baixo custo. $O$ gerente GGT foi perguntado com relação aos custos de mão de obra e responde no trecho 02: "com relação ao pessoal, nós pagamos mais que os concorrentes, e isso eu tenho certeza, pois apesar de nunca ter trabalhado em nenhuma outra indústria de bebidas, mas há seis anos que trabalho nesta empresa e sei que muitas pessoas, de outros fabricantes, tem o sonho de trabalhar aqui... Os salários são diferenciados e os funcionários também, pois procuramos gente que tenha certo potencial. A diferenciação daqui não é só no produto, mas também no atendimento".

Neste momento a empresa relata sua preocupação com as potencialidades dos funcionários e se apresenta como a que melhor paga os seus funcionários que os concorrentes, não possuindo as características de uma empresa líder em custo sob esse aspecto, mas sim com sua atenção voltada para a diferenciação.

O gerente GGT foi interrogado quando à questão da fatia do mercado que sua empresa alcança e o mesmo respondeu em seu discurso no fragmento 03: "como a maioria das empresas, a nossa é aberta a todo o público, mas assim, é uma empresa que pelo preço dela e pela qualidade 
que ela tem mesmo que a gente não faça uma seleção acaba acontecendo... Temos um público mais selecionado, realmente" .

Conforme Porter (1999), ao atingir a diferenciação pode, às vezes, tornar impossível a obtenção se uma alta parcela de mercado, pois nem todos os clientes estão dispostos a pagar por preços mais altos.

Ainda perguntando ao GGT se a empresa estabelece como foco um segmento de cliente específico com atendimento exclusivo, o gerente GGT respondeu que antes a empresa possuía uma clientela mais "clássica" e tradicional, devido ao produto pioneiro da empresa que foi o conhaque de alcatrão, mas que atualmente trabalha com um alcance maior atingindo a moda jovem com energéticos, adulta com bebidas alcoólica e infantojuvenil com bebidas não alcoólicas, tendo uma maior abertura e variedade de produtos. A empresa conseguiu atrair mais clientes como foi colocado quando cita que "foram os novos produtos que chamaram outros públicos".

Porter (1999) comenta que a estratégia de enfoque se refere à escolha de um "seguimento-alvo", indicando que a empresa deve se fixar em um segmento de mercado menor ao invés de ir atrás de um grande mercado. No caso da empresa $T$, está ampliando o seu enfoque para atender a maior parcela de mercado que sua estratégia de diferenciação permite.

Para Porter (1999), os métodos utilizados para diferenciação podem assumir muitas formas como projeto ou imagem da marca, tecnologia, desempenho e características dos produtos, serviços fornecidos, rede de fornecedores, qualidade dos insumos adquiridos para uma atividade e toda e qualquer atividade que oferece esta vantagem e benefícios aos clientes. As principais características de um produto segundo o autor são: tamanho, forma, cor, peso, desenho, material, tecnologia e ainda o seu desempenho em termos de confiabilidade, consistência, gosto, velocidade, durabilidade e segurança.

Existem também as clientes que desejam pagar mais caro por produtos diferenciados, pois tais produtos causam imagem, status e prestígio reforçando a diferenciação. $O$ gerente GGT relata que a empresa trabalha com os melhores e mais conceituados fornecedores do mercado e possui características específicas em seus produtos causando prestígio e status aos seus clientes. Essas afirmações podem ser mais bem percebidas em seu discurso, trecho 04: "nós temos um produto que é feito com uma água dezesseis vezes filtrada é feita uma seleção do melhor material para esse produto... Têm clientes que possuem boates ou casa de show que fazem pedidos somente dele e a gente se surpreende como a procura aumenta cada vez mais... Estes são produtos únicos".

Além disso, o gerente GGT expressa que o produto da empresa detém certo status e prestígio relatando que alguns clientes já comentaram que "basta olhar para a lata na mão de alguma pessoa e se tiver o símbolo da empresa já se sabe que o produto tem qualidade".

Os benefícios supracitados comprovam o valor do produto oferecido aos clientes de forma diferenciada fazendo de seus produtos únicos no mercado. Porter (1999) aborda que a empresa é recompensada pela sua singularidade por um "preço-prêmio". O mesmo relata no discurso do trecho 05: "acho que sim, porque nós somos representantes de uma 
cervejaria muito antiga e famosa e tem outras representantes com o mesmo produto e terceirizada pela mesma empresa e mesmo assim o nosso preço é bem superior porque temos nossa marca".

Com relação à concorrência, foi perguntado a GGT qual o posicionamento de seus produtos quanto à diferenciação em relação à concorrência. Esse relata: "têm outras empresas com preços compatíveis aos nossos, mas que a nossa a procura é bem maior devido à qualidade" (trecho 06).

Com relação aos concorrentes, o gerente afirma que os principais concorrentes são multinacionais produtoras de bebidas, pois, além de terem uma fatia maior do mercado, têm a capacidade de produzir suas próprias matérias-primas, o que se revela com uma vantagem competitiva para elas.

Porém, na visão do gerente, a grande dimensão dessas multinacionais, que revela sucesso no mercado, pode ser vista também como uma oportunidade para a empresa em estudo, pois devido a seu médio porte, consegue trabalhar com mais agilidade e tomar decisões de forma mais eficaz. De outro modo, as mesmas empresas que colocam como concorrentes, são vistas também como modelos a serem seguidos, de formas que alguns processos produtivos que são utilizados por elas, podem de alguma forma, se incorporar à realidade da empresa.

Referente aos novos entrantes, esse cita que, para entrar no ramo de fabricação de bebidas, são precisos altos investimentos, e com isso não é grande a probabilidade de novos entrantes no mercado, pois, segundo o entrevistado, quanto mais difícil o ramo, menos concorrentes terão. Essa visão difere da tida pelo gerente de produção da empresa, que acredita que nos próximos anos muitas fabricantes de bebidas serão abertas no estado do Rio de Janeiro. Acredita-se também que o mercado tem capacidade de aportar todos os negócios, mas só os melhores permanecerão. Além disso, a pretensão de crescimento é comum visão para todos os concorrentes, afirma o gerente da empresa.

Já em relação à barganha dos fornecedores, foram detectados os seguintes pontos com relação aos seus poderes de barganha:

- Em algumas situações, podem impor limites à quantidade comprada pela empresa; em outras não;

- Nunca podem oferecer produtos com qualidade inferior;

- Fazem negócios programados com a empresa. No caso, os insumos são comprados num período, para só serem entregues no período seguinte.

- Nunca fornecerem produtos com descontos inferiores aos dados para os concorrentes;

- Dependendo do desconto dado, podem fornecer produtos com prazos de pagamento mais curtos.

As condições oferecidas à empresa são diferentes das condições oferecidas aos seus concorrentes, pois depende do poder de barganha de cada um. Além disso, em caso de urgências, as condições podem se modificar, podendo ocorrer a chamada venda por urgência. 
Como a empresa atua no ramo de bebidas alcoólicas e não alcoólicas, os principais insumos necessários à sua produção são água, álcool, açúcar e corantes. Nesse caso, segundo seu gerente de produção, essa até teria capacidade de produzir seus insumos (integração vertical), mas não é interessante, tendo em vista todo o investimento e onerosidade necessária para tanto.

O restante dos insumos necessários advém de multinacionais, principalmente, pois, segundo o entrevistado, as grandes empresas nacionais fornecedoras já são, em suas palavras, "monopolizadas" pelos concorrentes. No entanto, mesmo sendo multinacionais as principais fornecedoras, não há dificuldades de acesso ou contato com elas.

E já a barganha dos clientes ou consumidores tem papel muito importante para o planejamento e direcionamento das ações da empresa. Dependendo da ocasião, eles têm capacidade de exigir preços mais baixos, maiores descontos, pagamentos mais dilatados, de desfrutar de serviços adicionais, de dispor de qualidade especial para o produto que lhes é fornecido, entre outras formas de barganha. Segundo o entrevistado, "tudo é negociado".

Para atender às necessidades dos consumidores, a empresa procura oferecer um atendimento que demonstre atenção para com esses, treinando para isso toda sua equipe de venda, de modo que haja um desenvolvimento de atendimento ao cliente uniformizado para toda a empresa e distribuidores, o que caracteriza uma forma de padronização em parceria, para melhor agradar o consumidor final. A qualidade dos seus produtos é sempre visada, e para isso a empresa faz testes laboratoriais em laboratórios próprios, em amostras, no início e fim da produção.

As exigências dos clientes costumam serem feitas através do Serviço de Atendimento ao Consumidor (SAC) e podem ou não ser atendidas pela empresa, dependendo de suas condições. Elas ainda diferem das exigências feitas aos concorrentes dessa, tendo em vista que cada empresa oferece produtos e serviços teoricamente diferentes.

Atualmente, os principais clientes da empresa em estudo são as redes de supermercados, pois essas atendem a todos os públicos e algumas lojas de varejo ou, ainda, lojas de conveniência da capital, do interior e outros estados.

A empresa, no intuito de não sofrer as consequências de possíveis produtos substitutos, procura oferecer como formas alternativas de satisfazer as necessidades dos clientes os produtos diferenciados, como, por exemplo, uma ótima logística, agilidade de suas ações, atenção primordial ao cliente, manutenção da qualidade e SAC. Os gastos tidos pela empresa para oferecer tais serviços não se traduzem em custos, já que é feito para beneficiar os negócios da empresa. Ou seja, os benefícios são maiores que os custos.

Constatou-se que a empresa adquiriu tradição, confiabilidade dos fornecedores e satisfação dos clientes, apresentando grande lucratividade no comércio e superando entraves. Compreendemos ainda a adoção de planejamento estratégico, a partir do estabelecimento de metas e estudos 
para a inserção em novos mercados para avaliar o setor, com vistas a melhorar as relações entre os fornecedores e clientes diretos.

Entretanto, a empresa não costuma fazer pesquisas para avaliar o desempenho da concorrência ou da satisfação dos consumidores com seus produtos, o que pode ser visto, de certa forma, como um ponto negativo, já que é de extrema importância a análise periódica de mercado no qual está inserido a empresa e para o sucesso de uma empresa tornam-se necessárias pesquisas de opinião. Críticas construtivas permitem à empresa detectar falhas e posteriormente melhorá-las. $O$ entrevistado afirma que para fins de avaliação de mercado, a empresa costuma utilizar-se de estatísticas, as quais trazem informações capazes de indicar quais produtos estão sendo mais comprados e quais são os que mais agradam os consumidores. E, a partir daí a empresa direciona suas estratégias, a fim de alavancar as vendas.

\section{CONCLUSÃO}

De acordo com os resultados obtidos neste trabalho, a empresa T está bem identificada quanto a sua estratégia empresarial. Utilizar as estratégias competitivas genéricas de Porter (1999) como base para enquadrar a empresa contribui para o melhor gerenciamento das estratégias em relação aos resultados, pois permite uma identificação das políticas estratégicas do segmento industrial da região.

A amostra utilizada da população foi adequada para a pesquisa e satisfez o propósito deste estudo. As técnicas e metodologias foram adequadas para atingir o objetivo geral deste estudo que visava identificar e estabelecer uma relação das estratégias competitivas genéricas com as cinco forças Porter e sua influência nos resultados obtidos pela empresa analisada. Tal fator foi percebido no processo investigativo na aplicação da entrevista na empresa, pois o gerente geral apresentou como agem as cinco forças competitivas na empresa e como ela usa os estudos para reagir a essas forças, formulando a estratégia atual de diferenciação em excelência operacional para ganhar alguma vantagem competitiva.

Por fim, este trabalho idealizou aplicar a análise do posicionamento estratégico da empresa T utilizando o modelo das cinco forças de Porter, em uma empresa fabricante de bebidas e chegou ao resultado de que ela busca focar na diferenciação do seu produto através da qualidade e nos serviços de apoio e suporte aos clientes buscando ter na excelência operacional seu diferencial em relação às competências organizacionais.

Sugere-se que novos estudos sejam feitos nas empresas do setor, principalmente em empresas denominadas de meio-termo, pois além de apresentar vertentes estratégicas quanto ao tratamento do custo, também apresentam diferenciação de forma simultânea. 


\title{
Porter Forces Framework and strategic positioning as a competitive differential: the case of a company in the beverage industry
}

\begin{abstract}
Beverage companies are organizations that are constantly looking for more efficient ways to meet customer needs. Each organization uses a variety of strategies to reach more buyers without compromising its existence and competitive advantage. This paper is based on the five competitive forces and the theory of generic competitive strategies of Porter, which establishes that the companies belonging to the market must have at least one of the three strategic approaches: differentiation, focus and leadership in cost Porter's five competitive forces will be identified and described, and how they influence the definition of competitive business strategy. Initially, a survey was made of the relationship of the strategies of the company under study with the theory presented by Porter and questionnaires were applied to the sector managers of the company in question. After analyzing these questionnaires, three sectoral clusters with valid approaches were identified. Subsequently, we selected the correlated answers that had greater affinity among the sectors and that better represented the results arranged about the proposed theory and, in this sample, an interview was made with the general manager. The result observed from the interview validated the analysis of the data found in the previously applied questionnaires, demonstrating compliance with the theoretical reference. It can be affirmed that, with the results obtained, it is valid the application of this theory in the commercial beverage company, which has been adapted to maximize the financial results and to improve the strategic positioning in relation to its competitors.
\end{abstract}

KEYWORDS: Beverages Sector. Porter's Competitive Forces Framework. Business strategy. 


\section{REFERÊNCIAS}

AKÇAGÜN, E.; DAL, V. The analyses of Turkish apparel industry by the Five Forces Model. Industria Textila, v. 64, n. 2, p. 115-119, 2013.

CHIAVENATO, I. Administração nos novos tempos, 4a ed., v. 2. Rio de Janeiro: Editora Campus, 2004.

COGAN, S., Administre a fila de espera de seus clientes. Disponível em: <http://www.geocities.com/infobusiness.geo/filaclientes.html> Acesso em 31/09/2017.

CUNHA, J. C. S. Estratégias competitivas e o poder de negociação dos compradores: estudo de caso em uma indústria de refrigerantes. Dissertação (Mestrado em Engenharia de Produção) - Programa de PósGraduação em Engenharia de Produção, Universidade Federal de Santa Maria, Santa Maria, 2006.

FORTE, S. H. A. C. Manual de elaboração de tese, dissertação e monografia, 5a ed. Fortaleza: UNIFOR, 2006.

GONÇALVES, C. A.; PAIVA JR., F. G. Competitividade e inovação influenciando o crescimento empresarial: a perspectiva dos empreendedores de empresas de base tecnológica. RPA Brasil, v. 2, p. 5562, 2006.

KOTLER, P. Marketing para o século XXI: como criar, conquistar e dominar mercados. São Paulo: Futura, 1998.

LAKATOS, E. M.; MARCONI, M. A. A metodologia do trabalho científico, 12 a ed. São Paulo: Atlas, 2002.

MAN, M. M. K. Supply Chain Management (SCM), environmental factors and porter five forces: A case study of Malaysia Airlines Berhad (MAB). International Journal of Supply Chain Management, v. 5, n. 3, p. 32-39, 2018.

NGUYEN, T. T. T. Management education as an industry and MBA as a product: revisiting joint MBA programs using Porters five forces model. Global Business and Economics Review, v. 19, n. 3, p. 356, 2017. 
NIELSEN BRASIL, Informações sobre categoriais de alimentos e bebidas.

Disponível em:

$<$ http://br.nielsen.com/reports/documents/OsProdutosMaisQuentesMund o_AlimentoseBebidas_pt-BR.pdf> Acesso em: 15/09/2017.

O'HARA, N. N.; NOPHALE, L. E.; O'HARA, L. M.; MARRA, C. A.; SPIEGEL, J. M. Tuberculosis testing for healthcare workers in South Africa: $A$ health service analysis using Porter's Five Forces Framework. International Journal of

Healthcare Management, v. 10, n. 1, p. 49-56, 2017. crossref

OLIVEIRA, D. P. R. Estratégia empresarial e vantagem competitiva: Como estabelecer, implementar e avaliar, 4a ed. São Paulo: Saraiva, 2002.

ORTEGA, A. G.; JALÓN, M. L. D.; MENÉNDEZ, J. A. R. A strategic analysis of collective urban transport in Spain using the Five Forces Model.

Investigaciones Europeas de Dirección y Economía de la Empresa, v. 20, n.

1, p. 5-15, 2014. crossref

PORTER, M. E. How competitive forces shape strategy. Harvard Business

Review, v. 57, n. 2, p. 137-145, 1979.

PORTER, M. E. Competição: estratégias competitivas essenciais. Rio de Janeiro: Campus, 1999.

PORTER, M. E. The five competitive forces that shape strategy. Harvard Business Review, v. 86, n. 1, p. 78-93, 2008.

PRAHALAD, C. K.; HAMEL, G. A competência essencial da incorporação. Rio de Janeiro: Campus, 1998.

QI, X. J.; SUN, M. T.; CHENG, M. The Corporate's Credit Evaluation of Engineering Supervision Based on Porter's Five Forces Model. Applied

Mechanics and Materials, v. 638-640, p. 2450-2454, 2014.

REBOUÇAS, F., Consumo de bebidas no Brasil. Disponível em:

<http://www.infoescola.com/economia/consumo-de-bebidas-no-brasil/> Acesso em: 30/05/2010.

SILVA NETO, R. Estratégias para o aumento da competitividade sistêmica de pequenas empresas de agrupamentos potenciais de baixa tecnologia e seu impacto no desenvolvimento local. Tese (Doutorado em Engenharia de Produção, Rio de Janeiro) - Programa de Pós-Graduação em Engenharia de 
Produção, Pontifícia Universidade Católica do Rio de Janeiro, Rio de Janeiro, 2002.

SUMPIO, B. E. Application of Porter's Five Forces Model and generic strategies for vascular surgery: should be stuck in the middle? Vascular, $v$. 21, n. 3, p. 149-156, 2013. crossref

WRIGHT, P. Administração estratégica. São Paulo: Atlas, 2000.

YIN, R. Case study research: Design and methods. Londres: Sage, 1994.

YETKIN, U. Revealing the Change in the Maritime Security Environment through Porter's Five Forces Analysis. Defence Studies, v. 13, n. 4, p. 458484, 2013.

Recebido: 19 mar. 2018

Aprovado: 26 mar. 2019

DOI: $10.3895 /$ gi.v15n2.8046

Como citar:

PRATA, D.F.R.F. et al. O modelo das forças de Porter e posicionamento estratégico como diferencial competitivo: o caso de uma empresa no ramo de bebidas. R. Gest. Industr., Ponta Grossa, v. 15, n. 2, p. 154-172, abr/jun 2019. Disponível em: <https://periodicos.utfpr.edu.br/rgi>. Acesso em: XXX. Correspondência:

Elias Rocha Gonçalves Júnior

Avenida Doutor Arthur Bernardes, 222, Parque Rosário, Campos dos Goytacazes, Rio de Janeiro, Brasil Direito autoral: Este artigo está licenciado sob os termos da Licença Creative Commons-Atribuição 4.0 Internacional.

\section{(c) (i)}




\section{Questionário}

- Sua empresa possui algum diferencial competitivo em relação aos seus concorrentes diretos? Quais? Porque geram vantagem competitiva?

- Como são os produtos que sua empresa negocia em relação ao Custo/benefício e benefícios em relação aos produtos de concorrentes?

- Como sua empresa avalia ou identifica as necessidades dos clientes?

- Esta empresa atende grupo específico de clientes ou a de vários segmentos de mercado? Qual ou quais são? - Sua empresa detém alguma vantagem na aquisição de suas mercadorias que contribua na redução dos custos? Qual?

- Como sua empresa administra os custos?

- Qual é a estratégia atual utilizada pela empresa?

- Com relação às forças competitivas, a empresa tem sofrido maior influência de qual (ais)?

- A estratégia atual da sua empresa tem influenciado nos resultados obtidos? Por quê?

- Você acredita que sua empresa sobreviverá por mais tempo no mercado em relação à concorrência? Por quê?

Perguntas para Indicadores De Estratégias Competitivas Genéricas Diferenciação.

- Esta empresa possui produtos diferenciados em relação aos seus concorrentes? Quais? Por que geram vantagem competitiva?

- O serviço que esta empresa oferece aos seus clientes tem um custo/benefício maior do que os oferecidos por seus concorrentes?

- Esta empresa cobra preços superiores aos seus concorrentes por oferecer produtos e serviços diferenciados?

- Os clientes desta empresa procuram possuir produtos e serviços diferentes?

- Esta empresa oferece mais treinamento aos seus funcionários do que seus concorrentes? Quais?

- Esta empresa possui liderança tecnológica em relação aos seus concorrentes diretos?

- Esta empresa possui um programa de atendimento a clientes melhor do que o dos seus concorrentes?

- Esta empresa inova e lança mais produtos novos no mercado do que seus concorrentes? 
Perguntas voltadas para Indicadores de Estratégicas Competitivas Genéricas - Liderança em custo.

- Esta empresa possui custos menores, comparando-a com seus concorrentes diretos?

- Esta empresa comercializa uma quantidade de produtos maior do que seus concorrentes?

- Os preços que esta empresa pratica geralmente são seguidos pela concorrência?

- Geralmente essa empresa possui preços mais baixos do que seus concorrentes?

- Esta empresa procura fazer negociações de compras sempre em grande volume?

- Esta empresa busca junto aos seus fornecedores melhores preços de aquisição e melhores condições de compra?

- Essa empresa se une às outras empresas do ramo para barganhar melhores preços de aquisição? Porque isso gera vantagem competitiva?

- Esta empresa visa possuir o menor preço do mercado? O que ela faz para alcançar essa meta?

Perguntas voltadas para indicadores de Estratégias Competitivas Genéricas - Enfoque.

- Esta empresa atende a um nicho específico de mercado? Qual?

- Esta empresa atende a clientes de diversos segmentos de mercado? Quais?

- Esta empresa possui uma linha reduzida de produtos? Quais? Isso gera vantagem competitiva?

- Esta empresa possui uma grande variedade de produtos? Quais? Isso gera vantagem competitiva?

- Esta empresa Esta empresa atende a clientes de diversas faixas de renda? Quais?

- Os produtos desta empresa são direcionados à uma classe social específica? Quais?

- Esta empresa atende a clientes de diversas faixas etárias? Quais?

Entrevista

- A estratégia atual da sua empresa tem influenciado nos resultados obtidos?

- Você acredita que sua empresa sobreviverá por mais tempo no mercado em relação à concorrência?

- Como sua empresa administra os custos? 
- Sua empresa detém alguma vantagem na aquisição de suas mercadorias que contribua na redução de custos?

- Esta empresa atende a clientes de um ou de vários segmentos de mercado?

- Como sua empresa busca atender as necessidades de seus clientes?

- Como são os produtos que sua empresa negocia em relação à qualidade e benefícios aos clientes?

- Como são os produtos que sua empresa negocia em relação aos seus concorrentes diretos?

- Com relação às forças competitivas, a empresa tem sofrido maior influência de qual (ais)?

Lista de Siglas

$P \& D$ - Pesquisa e Desenvolvimento

ABIR - Associação Brasileira das Indústrias de Refrigerantes

AMBEV - Companhia de Bebidas das Américas 